\title{
O VENCIMENTO DA DÍVIDA PÚBLICA CAMBIAL INFLUENCIA A TAXA DE CÂMBIO? UM ESTUDO ECONOMÉTRICO PARA O BRASIL NO PERÍODO 2003-2004*
}

\author{
Roberto Meurer ${ }^{\S}$ \\ Guilherme Valle Moura ${ }^{\text {a }}$ \\ Maurício Simiano Nunes ${ }^{\dagger}$
}

\begin{abstract}
RESUMO
Neste trabalho testou-se a hipótese de sinalização, sob a qual a taxa de câmbio entre o real e o dólar teria um comportamento diferente nos períodos que antecedem a liquidação da dívida pública interna cambial brasileira, com o que os detentores da dívida conseguiriam um rendimento acima do normal. Testes paramétricos lineares (regressão com variável dummy) e não-lineares (GARCH e mudança de regime markoviano), bem como não-paramétricos (Mann-Whitney e Wilcoxon) não detectaram comportamento anormal da variação da taxa de câmbio antes do vencimento da dívida pública cambial em 2003 e 2004. Com isto rejeita-se a hipótese de que a proximidade da data de vencimento da dívida pública poderia sinalizar ganhos extraordinários no mercado de câmbio, mas há alteração na volatilidade. Os testes de Mann-Whitney e Wilcoxon e o modelo GARCH com variável dummy detectaram comportamento diferente do retorno da taxa de câmbio no dia do vencimento da dívida pública, quando já não haveria interesse dos detentores dos títulos em elevar a cotação do dólar. Pelo modelo GARCH há uma aceleração da apreciação da moeda brasileira no dia do vencimento da dívida pública em relação ao restante dos anos de 2003 e 2004. O teste para mudança de regime markoviano, entretanto, não detectou retornos anormais no dia do vencimento da dívida pública cambial.
\end{abstract}

Palavras-chave: taxa de câmbio, dívida pública, sinalização, Brasil.

\begin{abstract}
The aim of this paper is to test the hypothesis that the exchange rate between the Brazilian real and the US dollar has a different behavior in the periods that precede the liquidation of dollar linked public debt, which could generate an above-normal return to the debt holders. The tests by dynamic regression with dummy variables, the non parametric Mann-Whitney and Wilcoxon tests, and Markov-switching models did not detect an abnormal behavior of the exchange rate in the days that precede the expiration of dollar indexed public debt in 2003 and 2004, rejecting the hypothesis that the expiration of dollar linked public debt is a signalization of abnormal returns on the foreign exchange market. However, that is a change in the volatility of the exchange rate. The Mann-Whitney and Wilcoxon tests and the GARCH model with dummy variables detected a different behavior of the exchange rate on the day of liquidation of dollar linked public debt, after the determination of the exchange rate used to settle the debt. The GARCH model detects an abnormal appreciation of the Brazilian real in comparison with the rest of the years 2003 and 2004. The Markov-switching model did not detect abnormal returns of the exchange rate on the day of expiration of public debt.
\end{abstract}

Key words: exchange rate, public debt, signalization, Brazil.

JEL classification: E44, G14, H63.

* Agradecemos aos pareceristas da revista pelas fundamentais sugestões. Os erros remanescentes são de nossa responsabilidade.

§ Departamento de Economia da Universidade Federal de Santa Catarina - UFSC. E-mail: rmeurer@mboxl.ufsc.br.

a Pós-Graduação em Economia Quantitativa da Christian-Albrechts-Universität zu Kiel - Alemanha . E-mail: gvallemoura@ gmail.com.

† Programa de Pós-Graduação em Economia da Universidade Federal do Rio Grande do Sul - UFRGS. E-mail: simianonunes@ bol.com.br.

Endereço para contato: Departamento de Economia - Centro Sócio Econômico - Campus Universitário - Florianópolis (SC) CEP: 88040-900.

Recebido em agosto de 2005. Aprovado em fevereiro de 2007. 


\section{INTRODUÇÃO}

Em períodos de incerteza sobre o futuro da economia e da política econômica brasileira, há um aumento da procura por moeda estrangeira, considerada um ativo mais seguro comparativamente aos denominados em moeda brasileira. Isto gera depreciação da moeda local, em caso de câmbio flutuante, ou redução das reservas internacionais, em caso de câmbio fixo. Isto ocorreu, recentemente, em 1998, pela percepção da impossibilidade de manutenção da política cambial e, em 2002, por causa das incertezas sobre a política econômica de um eventual governo de esquerda. Nessas situações o Banco Central oferece títulos da dívida pública ou derivativos cujas rentabilidades estão associadas à variação da taxa de câmbio entre a moeda brasileira e o dólar dos Estados Unidos, com o objetivo de reduzir a pressão compradora no mercado de divisas.

Quando ocorrem os vencimentos desses instrumentos de dívida pública atrelados à taxa de câmbio, os seus detentores poderiam obter ganho adicional se ocorresse uma depreciação da moeda brasileira. Considerando um regime de taxa de câmbio flutuante, a lógica deste argumento baseiase no fato de que os detentores dos títulos a vencer teriam interesse em elevar as cotações da moeda dos Estados Unidos. Com isso, receberiam maior quantidade de reais na data de liquidação dos títulos, funcionando, assim, como uma espécie de sinalização de ganhos ao mercado como um todo.

Os estudos de eventos, tradicionais na área de finanças, especialmente em mercado de ações, possibilitam a verificação de rendimentos anormais associados a um determinado evento. Exemplos para o mercado brasileiro são a volatilidade das taxas Selic e CDI com a aproximação de reuniões do Copom (Britto e Taciro JR., 2002) e a antecipação de participantes do mercado à política monetária (Tabak, 2003). Identicamente, a taxa de câmbio também pode ser afetada por intervenções do Banco Central e pela classificação do risco soberano para a dívida denominada em moeda externa. Payne e Vitale (2003), aplicando a metodologia de estudo de eventos às intervenções esterilizadoras do Banco Central da Suíça, mostram que elas afetam a taxa de câmbio ${ }^{1}$. Brooks et al. (2004), destacam que uma piora na classificação de risco levaria à desvalorização da moeda local, enquanto a melhora na classificação não gera a valorização. ${ }^{2}$

Em termos de aplicação da teoria de sinalização, destacam-se os ganhos anormais nos retornos das ações no período precedente aos desdobramentos ou pagamento de dividendos das ações, os chamados stock splits e stock dividends (Fama et al., 1969; Grimablatt, Masulis e Titman, 1984; Brennan e Copeland, 1988; e Kadiyala e Vetsuypens, 2002).

A importância do tema decorre de a taxa de câmbio ser um dos principais preços da economia, influenciando as decisões de produção e alocação de recursos no nível microeconômico. Existindo dívida pública atrelada à moeda estrangeira, as alterações na taxa de câmbio influenciarão o volume da dívida, seu risco e a necessidade de financiamento do setor público. No entanto, apesar da importância da taxa de câmbio e de afirmações no noticiário financeiro de que ocorrem elevações na taxa de câmbio por causa do vencimento da dívida cambial, não temos conhecimento de teste formal para esse fato no Brasil.

Por este motivo, no presente trabalho procurou-se testar a hipótese de que a taxa de câmbio tem uma elevação anormal quando ocorrem vencimentos de instrumentos de dívida pública cambial, o que possibilitaria ganhos excepcionais para os detentores dos títulos, às custas do governo. Isto significaria uma sinalização ao mercado de uma possível desvalorização anormal da moeda

1 Entretanto, a análise da intervenção do Banco Central do Brasil no mercado de câmbio não seria simples, dado o caráter não pontual dessas intervenções, como pode ser inferido de uma análise dos fatores condicionantes da base monetária, e é merecedora de maior investigação.

2 As mudanças na classificação do risco soberano brasileiro em 2003 e 2004 foram apenas marginais. 
brasileira às vésperas do vencimento dos títulos. A ocorrência de comportamento anormal da taxa de câmbio próximo ao vencimento de dívida pública cambial foi testada por meio dos testes não-paramétricos de Mann-Whitney e Wilcoxon e os testes paramétricos lineares com variáveis dummy e não-lineares (GARCH e mudança de regime markoviano) para os anos de 2003 e $2004{ }^{3}$ Em termos gerais, os resultados indicaram para a rejeição da hipótese de ocorrência de desvalorização superior da moeda brasileira nos dias anteriores ao vencimento da dívida pública nos período estudado, ou seja, a hipótese de que a proximidade da data de vencimento da dívida pública poderia sinalizar ganhos extraordinários no mercado de câmbio foi rejeitada, mas há alteração na volatilidade da taxa de câmbio. Por outro lado, detectou-se um comportamento diferente da taxa de câmbio no dia do vencimento, após estar definida a taxa segundo a qual é liquidada a dívida cambial.

O trabalho está estruturado em cinco tópicos, incluindo esta Introdução. Na Seção 2 discutem-se os dados utilizados, o contexto do mercado cambial brasileiro no período analisado e as possibilidades teóricas de abordagem de anomalias no mercado cambial. Na Seção 3 apresenta-se a metodologia utilizada, na Seção 4 são apresentados os resultados e na Seção 5 são destacadas as principais conclusões.

\section{MODELOS TEÓRICOS, DADOS E CONTEXTO DO MERCADO CAMBIAL}

\subsection{Modelos teóricos}

O comportamento da taxa de câmbio é importante do ponto de vista macroeconômico, haja vista que a mesma consiste em um dos principais preços da economia. Por outro lado, as decisões que levam à formação da taxa de câmbio, mormente em um regime de câmbio flutuante, são microeconômicas. Disto resulta a importância de se conhecer o funcionamento e a estrutura desse mercado. É necessário enfatizar que a manipulação da taxa de câmbio aqui considerada não se refere às operações de compra e venda alternadas, com possibilidade de ganhos pela diferença de preços entre as transações (Huberman e Stanzl, 2004), porque as transações que influenciam a taxa de referência ocorrem no mercado interbancário, sem necessariamente refletir-se no mercado primário.

Uma abordagem tradicional para a análise do mercado cambial, sistematizada e formalizada em Lyons (1996, 1997), considera que o mercado é organizado em torno de corretores que competem entre si e fazem as negociações com os demandantes e ofertantes primários, que são atomizados. Os corretores possuem informação assimétrica, porque a transparência do mercado é limitada. Os demandantes e ofertantes primários percebem os fluxos de ordens com ruído, enquanto as ordens primárias fornecem informações importantes para os corretores. Como a informação não é perfeita, os corretores podem utilizá-la para reduzir a sua exposição ao risco, repassando posições indesejadas a outros corretores caso não o tenham feito junto aos participantes primários. Nestas operações diretas os ofertantes e demandantes primários não têm condições de participar. Isto é possível porque, como o mercado não é totalmente transparente, há um lapso de tempo entre as ordens e a percepção generalizada desta informação no mercado, durante a qual o corretor avesso ao risco pode eliminar a sua posição indesejada. O comportamento otimizador dos corretores é operar com transparência limitada. A transparência total reduziria a capacidade de repassar riscos

3 A instabilidade e as alterações na volatilidade são importantes quando se modela o mercado cambial (Malik, 2003), mas isto está além dos objetivos deste trabalho. Também não se considera a influência do tamanho do mercado cambial que, no Brasil, está se reduzindo (Garcia e Urban, 2004) e a intervenção do Banco Central diretamente no mercado de divisas. 
de posições, enquanto a ausência de transparência inibiria a participação de não-corretores no mercado. "Undesired inventories are essential for capturing this hot potato process, and the simultaneous trade feature is our means of producing these disturbances" (Lyons, 1996, p. 242). Estes resultados do modelo são compatíveis com o baixo spread entre preços de compra e venda no mercado cambial, apesar de a transparência não ser total, o que impede a realização de operações de arbitragem entre corretoras.

Caso houvesse um mercado centralizado, do tipo bolsa de valores, em que a transparência é imposta e o melhor negócio é assegurado, o problema da manipulação da taxa referencial poderia ser eliminado. Mesmo que existissem participantes do mercado com informação privilegiada, os preços poderiam ser estabelecidos de maneira eficiente no sentido semiforte (Kyle, 1985), porque os preços continuariam sendo determinados principalmente pelos fluxos primários.

No caso concreto que se está analisando, ao perceber que o mercado interbancário está manipulando a taxa de câmbio para assegurar o recebimento de um maior volume de moeda doméstica, o Banco Central teria de vender moeda estrangeira ao preço praticado, que está acima do equilíbrio entre oferta e demanda. ${ }^{4}$ A questão do Banco Central será decidir se a mudança na taxa é genuína ou manipulação. Como as negociações no mercado interbancário (secundário) não têm de ser registradas instantaneamente e, de fato, são registradas com defasagem (Garcia e Urban, 2004), e os negócios podem ser efetuados sem assegurar o preço a outros participantes, o Banco Central pode não ter as condições práticas de interferir no mercado para evitar a manipulação. Por outro lado, em um mercado eficiente em que ocorressem tentativas de manipulação de taxas, seriam atraídos vendedores para aproveitar o afastamento do preço de seu nível normal, com o que o preço voltaria ao nível de equilíbrio.

Caso o mercado fosse caracterizado por competição imperfeita, isto teria como conseqüência um preço diferente do preço competitivo, mas não estaria associado à possibilidade de manipulação das taxas, porque a interação entre compradores e vendedores continuaria gerando um preço de equilíbrio, o que não ocorre em caso de manipulação, em que se caracterizariam transações fictícias. O caso analisado, portanto, está associado à falta de transparência no mercado. O interessante é que as operações entre os corretores (interbancário) e os ofertantes e demandantes primários não necessitam necessariamente seguir as taxas que poderiam estar sendo manipuladas. Com isto existiria apenas um perdedor na operação, o Banco Central, que pagará a taxa artificialmente elevada.

Dessa forma, considerando a assimetria de informação gerada pela falta de transparência no mercado, o vencimento da dívida pública cambial pode servir como uma espécie de sinalização de possíveis ganhos anormais aos participantes do mercado cambial no período precedente ao vencimento dessas dívidas. A aplicação da teoria de sinalização no mercado financeiro tem recebido destaque na observação de retornos anormais das ações no período precedente ao anúncio dos desdobramentos e dividendos, os stock splits e stock dividends. Fama et al. (1969), por exemplo, verificaram a existência de retornos anormais positivos antes da realização dos desdobramentos das ações. Lakonishok e Lev (1987) verificaram elevadas taxas de crescimento dos ganhos para empresas que realizaram os stock splits. Analogamente, a aplicação da teoria de sinalização ao estudo proposto pode ser caracterizada pela possibilidade de ganhos anormais aos detentores da moeda americana quando do vencimento da dívida pública cambial. A lógica para este argumento baseia-se no fato de que os detentores dos títulos a vencer teriam interesse e poder para elevar as

4 O preço gerado através do fluxo de negociações pode afastar-se dos fundamentos macroeconômicos por diferentes motivos, como explorado em Evans e Lyons (2004).

5 Existe a possibilidade de existirem outros perdedores, também afetados pela mesma taxa, como é o caso das operações de mercado futuro de câmbio, que não estão sendo analisadas neste trabalho. 
cotações da moeda americana e, com isso, receber maior quantidade de reais quando da liquidação dos títulos. No entanto, esses ganhos anormais não estão livres de custo, haja vista que se a compra de moeda estrangeira por parte dos detentores dos títulos da dívida para influenciar a cotação do dólar for efetiva, os mesmos podem incorrer em prejuízos pelo custo de oportunidade em relação a outros investimentos ou decorrentes da possível desvalorização da moeda americana. Portanto, sob a hipótese inerente à teoria da sinalização, a proximidade do vencimento da dívida pública cambial deve gerar um ganho anormal aos detentores desses títulos, bem como aos possuidores de ativos denominados na moeda americana, decorrente da valorização dessa frente ao real.

\subsection{Dados e contexto do mercado cambial}

O regime cambial brasileiro é, desde meados de janeiro de 1999, de flutuação, sujeita a intervenções do Banco Central, embora não haja uma regra quanto a essas intervenções. Em outras palavras, a flutuação do real é suja, mas ocorrem períodos sem intervenção da autoridade monetária no mercado. As preocupações do Banco Central brasileiro com o câmbio, entretanto, são evidentes, especialmente se considerado que o país está em um regime de metas inflacionárias.

A taxa de câmbio utilizada neste trabalho é a média diária divulgada pelo Banco Central, conhecida como "ptax" (denominação que tem origem na transação ptax800 do Sisbacen, o sistema de informações do Banco Central do Brasil, que fornece o valor dessa taxa). Esta taxa é a média das taxas ponderada pelo valor das operações no mercado interbancário efetuadas em um determinado dia. O valor desta taxa de câmbio no dia útil imediatamente anterior é utilizado para a liquidação das operações com títulos públicos indexados à variação do dólar americano.

Os principais títulos públicos atrelados ao câmbio no mercado brasileiro são as NTN-D (Notas do Tesouro Nacional, série D) e as NBC-E e NBC-F (Notas do Banco Central, séries E e F), além de operações com derivativos. Os vencimentos desses títulos e os respectivos valores foram coletados nas Notas para a Imprensa - Mercado Aberto, publicadas mensalmente pelo Banco Central do Brasil (www.bcb.gov.br). De cada Nota para a Imprensa foram considerados apenas os dados para o mês imediatamente posterior, já que novas operações podem alterar a posição. Como poderiam ocorrer negociações desses títulos com o Banco Central durante o próprio mês, também foram verificadas as operações do Banco Central no mercado secundário ao longo do mês, obtidas na mesma Nota para a Imprensa do mês imediatamente subseqüente. Esta verificação não detectou operações do Banco Central com os títulos ou derivativos no próprio mês do vencimento.

Um elemento complicador para o estudo foi a utilização de derivativos por parte do Banco Central para intervenção no mercado cambial, especificamente por meio de operações de swap. Estas operações, autorizadas na Resolução 2.939, de 26 de março de 2002, permitiram ao Banco Central efetuar operações de swap de taxas de juros (taxa Selic - a taxa básica de juros da economia brasileira) e variação cambial. O instrumento para isso são as LFT (Letras Financeiras do Tesouro), cujo rendimento é dado pela taxa Selic. As operações de swap permitiram ao Banco Central maior liberdade de intervenção indireta no mercado cambial sem que necessitasse efetuar as operações com todo o volume de títulos indexados ao dólar. Esta maior flexibilidade das operações do Banco Central possibilitou que parcelas da dívida cambial a vencer fossem renegociadas antes do seu vencimento, por meio de operações de swap cambial a serem liquidadas na data de vencimento do título público e atrelada a LFTs de vencimentos diversos, por meio de leilões como os usuais na colocação de títulos públicos.

A partir do final de março de 2002, estas operações foram usadas com freqüência pelo Banco Central, para aumentar indiretamente a oferta de títulos públicos cambiais, cuja demanda como 
substitutos da moeda estrangeira no mercado à vista era crescente, e para substituir os títulos cambiais que iriam vencer. Desta forma, o Banco Central poderia oferecer swaps cambiais ao mercado nos períodos anteriores ao vencimento de títulos cambiais, o que, em termos práticos, reduzia o volume de títulos cambiais que efetivamente teriam de ser pagos no seu vencimento. Para efeito deste trabalho foram consideradas as operações efetuadas antecipadamente para reduzir o valor a ser liquidado, sem considerar a data em que foi feita a operação de swap.

Em 2003 ocorreram vencimentos de dívida pública cambial em 49 dias, totalizando US\$ 45 bilhões, dos quais foram liquidados 14,8 bilhões, o que fez parte da estratégia do governo brasileiro de redução da exposição cambial na dívida interna. Para este trabalho foram considerados 13 vencimentos, em que venceram US $\$ 20,9$ bilhões e foram liquidados US $\$ 13,5$ bilhões. Não foram considerados os dias com vencimentos em volume inferior a US $\$ 50$ milhões e aqueles em que houvesse superposição dos cinco dias anteriores com outro vencimento, mantendo o de maior valor, além daqueles em que ocorreu a rolagem integral da dívida, ou seja, não houve liquidação efetiva. Também não foi considerada a liquidação de 2 de janeiro de 2003, para a qual a taxa de câmbio para liquidação foi estabelecida em 2002. A redução de 49 para 13 vencimentos no ano de 2003 gerou perda de apenas US $\$ 1,3$ bilhão em liquidações de dívida no ano, mas reduziu enormemente a poluição nos dados.

Os 42 vencimentos de dívida cambial que ocorreram em 2004 totalizaram US \$25,7 bilhões, dos quais foram liquidados US\$24,4 bilhões. Com os mesmos critérios aplicados a 2003, foram considerados 13 vencimentos, dos quais foram liquidados US $\$ 14,8$ bilhões. O vencimento de 15 de dezembro de 2004 também não foi considerado porque, em função das operações com derivativos, o governo passou a ser credor em moeda estrangeira, o que significaria interesse do mercado em reduzir o valor do dólar próximo ao vencimento. Por isso a amostra utilizada foi até 30 de novembro de 2004. A política mais agressiva de redução da dívida cambial interna em 2004 explica o maior volume de liquidações em relação aos vencimentos ocorridos no ano. ${ }^{6}$

A possibilidade de elevação manipulada das taxas de câmbio associadas aos vencimentos dos títulos cambiais implica que as transações "artificiais" no mercado da divisa, apelidadas no mercado financeiro de "Zé-com-Zé”, não atraiam vendedores efetivos a essa taxa. Caso algum vendedor efetivamente interessado em vender dólares à taxa artificialmente elevada entrasse no mercado, a cotação cairia, impossibilitando o processo, o que é possível com a falta de transparência no mercado (Garofalo Filho, 2002a e Garcia e Urban, 2004). ${ }^{7}$ Entretanto, depois de determinada a taxa à qual os títulos públicos são liquidados, não haveria incentivos à continuidade da cotação elevada, o que levaria ao retorno às cotações normais. Caso exista manipulação de taxas por causa do vencimento de títulos cambiais, espera-se que os testes mostrem a ocorrência de aumento do valor do dólar no dia ou dias anteriores ao vencimento da dívida ou queda no dia da liquidação.

\section{Metodologia E Hipótese}

Mackinlay (1997) faz uma resenha da literatura sobre estudos de eventos em finanças. Este método vem sendo utilizado desde a década de 1930 e com crescente nível de sofisticação. As pri-

6 Embora a possibilidade de obtenção de ganhos extraordinários no vencimento dos títulos cambiais não seja restrita aos anos de 2003 e 2004, este trabalho analisa apenas os vencimentos da dívida ao longo desses anos, porque há um maior número de vencimentos em que a dívida é efetivamente liquidada. A importância dessa possibilidade se dá pela elevada participação dos instrumentos indexados ao dólar na dívida pública mobiliária interna, que era de 29,5\% em dezembro de 2001, passando para $37 \%$ em dezembro de 2002 e recuando para 20,5\% em dezembro de 2003 e 9,5\% em 2004.

7 Uma completa história do mercado cambial brasileiro, suas peculiaridades e atuação das autoridades monetárias pode ser consultada em Garofalo Filho (2002b). 
meiras tarefas são definir o evento de interesse e o seu período - a janela do evento, que normalmente é maior do que o período específico do evento. O terceiro passo seria determinar os critérios para a inclusão de empresas no estudo, o que não é aplicável ao presente trabalho, que trata de um mesmo evento se repetindo ao longo do tempo e não um evento se repetindo em diferentes empresas em momentos distintos. Finalmente, deve-se calcular o retorno anormal.

O retorno anormal é a diferença entre o retorno observado e o retorno normal. O retorno normal é definido como o retorno esperado que não esteja condicionando ao evento. As maneiras usuais de definir o retorno normal são retorno médio constante e retorno ajustado ao mercado. No caso do retorno constante, comparam-se os retornos ocorridos na janela do evento com a média de retorno do ativo ao longo do tempo, o que equivale supor que o seu retorno esperado é constante. Para retorno ajustado ao mercado, os retornos normais são obtidos por meio da estimativa de um modelo estatístico que compara os retornos observados do ativo com alguma carteira de mercado. Também são utilizados modelos fatoriais e modelos de apreçamento de ativos como o CAPM (Modelo de Apreçamento de Ativos de Capital) ou APT (Teoria de Preço de Arbitragem).

Um procedimento usual nos estudos de evento é o teste da diferença da média dos retornos na janela de evento com o restante, por meio de um teste $t$, o que não é aplicável ao caso aqui estudado devido à não-normalidade dos dados de variação cambial. Entretanto testes não-paramétricos podem ser usados neste caso (para uma série de estatísticas não-paramétricas, ver Sheskin, 2004). O teste não-paramétrico concorrente ao teste $t$ é o teste de Mann-Whitney (Mann e Whitney, 1947), que não requer nenhuma hipótese sobre a distribuição dos dados. Este teste é usado para testar a hipótese nula de que os dois conjuntos de dados provêm de uma distribuição com os mesmos parâmetros contra a hipótese alternativa de que os dados provêm de distribuições com parâmetros diferentes. Apesar de ser um teste não-paramétrico, o teste considera que as distribuições das duas amostras têm a mesma forma. O teste de Mann-Whitney é baseado na comparação de todas as observações $x_{i}$ do primeiro conjunto de dados com todas as observações $y_{j}$ da segunda amostra. Podem ser feitas $n_{x} n_{y}$ comparações, onde $n_{i}$, para $i=x, y$, é o número de observações na amostra $i$. No caso das duas distribuições terem a mesma mediana, cada $x_{i}$ tem a mesma chance de ser maior que cada $y_{j}$. Tem-se portanto, sob a hipótese nula, $P\left(x_{i}>y_{j}\right)=\frac{1}{2}$ e sob a hipótese alternativa $P\left(x_{i}>y_{j}\right) \neq \frac{1}{2}$. Calcula-se, então, o número de vezes que $x_{i}$ foi maior que $y_{j}$, denotado $U_{x}$, bem como a quantidade $U_{y}$. O menor valor entre $U_{x}$ e $U_{y}$ é usado para achar a probabilidade de se encontrar o valor $\min \left\{U_{x}, U_{y}\right\}$ (por meio da tabela de Mann-Whitney), quando as duas amostras provêm da mesma distribuição.

Também é utilizado o teste não-paramétrico para mediana igual a zero de Wilcoxon (Wilcoxon, 1945), para o qual não é necessário assumir independência das amostras.

Outra alternativa menos utilizada na literatura de finanças, pertinente para o problema aqui analisado, é a utilização de uma análise de regressão. Para tanto, utiliza-se uma regressão com variáveis dummy para os dias da janela do evento (equação 1). A equação a ser testada é:

$$
R_{t}=\alpha_{1}+\alpha_{2} D_{t}+\varepsilon_{t}
$$

onde $R_{t}$ é a variação cambial no período $t$ e $D_{t}$ é a variável dummy, que tem valor 1 no dia que se quer testar e 0 nos demais. Assim, se o coeficiente $\alpha_{2}$ for estatisticamente diferente de zero, há indicação de que ocorra uma variação anormal da taxa de câmbio no dia identificado pela variável 
dummy. A idéia subjacente é que, caso haja um comportamento diferente nos dias anteriores ou no dia do vencimento dos instrumentos cambiais, rejeita-se a hipótese nula de que o valor de $\alpha_{2}$ seja igual a zero e verifica-se que a proximidade do vencimento da dívida pública cambial pode sinalizar um retorno anormal da moeda americana ante o real.

Por fim, a influência da intervenção cambial em relação à dívida pública pode ser testada via modelos não-lineares. Os modelos utilizados neste estudo são o modelo GARCH e mudança de regime markoviano. A utilização de um modelo de heteroscedasticidade condicional auto-regressiva é justificada devido à forte influência das diferentes variabilidades dos erros de previsão no decorrer de uma sucessão cronológica. Essas diferentes variabilidades, comuns em séries financeiras como preços das ações e taxas de câmbio, se devem geralmente à volatilidade inerente ao mercado financeiro, ocasionada por notícias, suas interpretações e alterações de expectativas. No modelo de heteroscedasticidade auto-regressiva generalizada - GARCH - (Bollerslev, 1986), a variância condicional pode ser escrita como um processo Arma $(p, q)$. O processo que gera os erros pode ser descrito por:

$$
\varepsilon_{t}=v_{t} \sqrt{h_{t}}
$$

na qual $\sigma_{v}^{2}=1 \mathrm{e}$

$$
h_{t}=\alpha_{0}+\sum_{i=1}^{q} \alpha_{i} \varepsilon_{t-1}^{2}+\sum_{i=1}^{p} \beta_{i} h_{t-1}
$$

com $v_{t}$ sendo um processo de ruído branco que é independente das realizações passadas de $\varepsilon_{t-i}$ - A média condicional e incondicional de $\varepsilon_{t}$ será igual a zero e a sua variância condicional será dada por $h_{t}$ na equação (2) (Enders, 1995). Portanto, a equação (1) é ampliada para um modelo univariado auto-regressivo com dummies (de intercepto e de inclinação), considerando um processo heteroscedástico condicional para os resíduos, captando as possíveis volatilidades da variação da taxa de câmbio.

Além disso, quando uma série de tempo está sujeita a quebras estruturais, ocorrem não-linearidades e as hipóteses dos modelos lineares de estacionaridade e normalidade são violadas. Os modelos de mudança de regime markoviano levam em consideração esta não-linearidade. A idéia por trás destes modelos é que os parâmetros do processo estocástico são variantes no tempo, porém condicionais à variável de regime $S_{t}$. Essa variável indica a possibilidade de existência de diversos estados de mundo. Seja $M$ o número de regimes possíveis de forma que $s_{t} \in\{1, \ldots, M\}$. Então a densidade de probabilidade condicional do vetor de série de tempo observado, $y_{t}$, é dada por:

$$
p\left(y_{t} \mid Y_{t-1}, s_{t}\right)=\left\{\begin{array}{ccc}
f\left(y_{t} \mid Y_{t-1}, \theta_{1}\right) & \text { se } & s_{t}=1 \\
\vdots & & \vdots \\
f\left(y_{t} \mid Y_{t-1}, \theta_{1}\right) & \text { se } & s_{t}=M
\end{array}\right.
$$

onde $Y_{t-1}$ são as observações $\left\{y_{t-j}\right\}_{j=1}^{\infty}$. O vetor de parâmetros, $\theta$, depende do regime que prevalece em $t$, de forma que $\theta_{m}$ é o vetor de parâmetros no regime $m=1, \ldots, M$. 
Em modelos de mudança de regime markoviano, o processo gerador dos regimes é uma cadeia de Markov ergódica com número finito de estados $s_{t}=1, \ldots, M$, que são definidos pela probabilidade de transição:

$$
p_{\mathrm{ij}}=\operatorname{Pr}\left(s_{t+1}=j \mid s_{t}=i\right), \sum_{j=1}^{M} p_{i j}=1 \forall i, j \in\{1, \ldots, \mathrm{M}\},
$$

onde $p_{i M}=1-p_{i 1}-\ldots-p_{i M-1}$ para $i=1, \ldots, M$ (Hamilton, 1994).

A principal característica deste tipo de cadeia de Markov é que as probabilidades de transição para o próximo regime dependem apenas do regime em vigor, o que simplifica a modelagem e a estimação. A estimação é feita por meio de uma versão do algoritmo em Dempster, Laird e Rubin (1977), conhecida como filtro BHLK. O software utilizado é MSVAR, desenvolvido por Hans Martin Krolzig. Krolzig (1997) apresenta uma discussão detalhada do método de estimação.

A hipótese do modelo consiste em verificar uma mudança de regime entre os períodos com e sem vencimento de dívida pública cambial e os possíveis retornos anormais auferidos pelos portadores de títulos cambiais na janela do evento. Caso haja uma mudança de regime, os ganhos anormais dos portadores de títulos públicos no período precedente ao vencimento da dívida pública cambial, remete à hipótese de sinalização ao mercado de possíveis retornos acima da média.

\section{Resultados}

Os testes para a verificação da ocorrência de variação anormal da taxa de câmbio próximo ao vencimento de títulos públicos foram efetuados por meio dos testes não-paramétricos de MannWhitney e Wilcoxon, modelos de regressões lineares com variáveis dummy e não-lineares GARCH e mudanças markovianas.

\subsection{Testes de Mann-Whitney e Wilcoxon}

O teste de Mann-Whitney foi realizado para testar o comportamento da taxa de câmbio no dia anterior ao vencimento e no dia do vencimento de dívida pública cambial. Para isso os dados foram divididos em dois conjuntos de amostras diferentes. No primeiro conjunto, foram separados da amostra total de retornos os retornos do dia anterior ao vencimento de títulos da dívida cambial brasileira, para testar se há diferença de comportamento entre o dia anterior ao vencimento e os demais dias. Dentro deste conjunto, realizou-se o teste para os anos de 2003 e 2004 conjuntamente, bem como para os dados separados por ano. A Tabela 1 mostra os resultados. Para efetuar o teste para a ocorrência de comportamento distinto no dia do vencimento em relação aos demais dias, a amostra total também foi dividida e foram efetuados os testes para todo o período e para 2003 e 2004 separadamente. 
Tabela 1 - Resultados do teste de Mann-Whitney

\begin{tabular}{lcc}
\hline AMOSTRA & ESTATISTICA $t$ & PROB. \\
\hline 2003 e 2004 excluindo $t-1$ & 1.4379 & 0.1504 \\
2003 excluindo $t-1$ & 2.2479 & 0.0247 \\
2004 excluindo $t-1$ & 0.4994 & 0.6175 \\
& & \\
2003 e 2004 excluindo $t-0$ & 0.8714 & 0.3835 \\
2003 excluindo $t-0$ & 0.0399 & 0.9688 \\
2004 excluindo $t-0$ & 0.4142 & 0.6797 \\
\hline
\end{tabular}

Obs: valores em negrito denotam rejeição da hipótese nula com 95\% de confiança.

Para o(s) dia(s) anterior(es) ao vencimento, o teste indica diferentes distribuições para os retornos em 2003, porém não em 2004, ou 2003 e 2004 conjuntamente. O teste para o dia do vencimento indica que há comportamento diferente da taxa de câmbio nesse dia, embora não seja possível afirmar se a diferença significa um retorno anormal. $O$ fato de haver comportamento distinto no dia do vencimento pode indicar que as tentativas de elevação artificial da taxa de câmbio nos dias anteriores ao vencimento da dívida cambial cessam, o que gera comportamento distinto do retorno da taxa de câmbio no dia do vencimento da dívida.

É interessante perceber que este é um teste para diferenças na distribuição, o que o torna mais geral que um teste para diferença de médias. Portanto, é necessário realizar outros testes para se confirmar se a diferença detectada por este teste é mesmo devida à média ou a outro parâmetro da distribuição (ou até mesmo devido a diferentes funções de distribuição). Além disso, o teste de Mann-Whitney assume que as duas amostras são independentes. Essa hipótese, porém, só seria satisfeita se os retornos cambiais se comportassem como random walks.

Para testar a robustez dos resultados, todas as séries são testadas com teste não-paramétrico para mediana igual a zero de Wilcoxon (Wilcoxon, 1945). Desta forma, pode-se testar cada série individualmente e não é necessário assumir independência das amostras. Os resultados da Tabela 2 confirmam os resultados do teste de Mann-Whitney, em que os retornos do dia anterior ao vencimento de títulos cambiais no ano de 2003 são estatisticamente diferentes de zero. É interessante perceber que a estimativa para a mediana dessa distribuição é positiva, indicando possíveis alterações no sentido da influência na formação da taxa de câmbio.

Tabela 2 - Resultado do teste de Wilcoxon para $t-1$

\begin{tabular}{lccc}
\hline AMOSTRA & MEDIANA & ESTATISTICA $t$ & PROB. \\
\hline 2003 e 2004 excluindo $t-1$ & -0.1047 & 2.0297 & 0.0416 \\
2003 e $2004 t-1$ & 0.0796 & 0.9970 & 0.3187 \\
2003 excluindo $t-1$ & -0.1248 & 2.0879 & 0.0368 \\
$2003 t-1$ & 0.2387 & 2.0266 & 0.0426 \\
2004 excluindo $t-1$ & -0.0493 & 1.1240 & 0.2610 \\
$2004 t-1$ & -0.0930 & 1.1299 & 0.2585 \\
& & & \\
2003 e 2004 excluindo $t-0$ & -0.0755 & 1.8050 & 0.0711 \\
2003 e $2004 t-0$ & -0.2278 & 1.5496 & 0.1212 \\
2003 excluindo $t-0$ & -0.1040 & 1.6030 & 0.1089 \\
$2003 t-0$ & -0.1361 & 0.5590 & 0.5761 \\
2004 excluindo $t-0$ & -0.0420 & 0.9615 & 0.3363 \\
$2004 t-0$ & -0.1038 & 1.5647 & 0.1176 \\
\hline
\end{tabular}

Obs: valores em negrito denotam rejeição da hipótese nula com 95\% de confiança. 


\subsection{Teste com regressão dinâmica e variável dummy}

No segundo teste, variáveis dummy são inseridas na equação de regressão para verificar um possível retorno anormal na data do vencimento. Na primeira parte, testa-se o modelo restrito contendo somente a variável dummy como explicativa, conforme Tabela 3.

Tabela 3 - Resultado da regressão - variável dependente: variação cambial 2003-2004

\begin{tabular}{lcccc}
\hline & Coeficiente & Erro Padrão & Estatística $t$ & Probabilidade \\
\hline Vcto & -0.098 & 0.122 & -0.808 & 0.4190 \\
\hline
\end{tabular}

Obs: a variável Vcto representa a dummy para os dias de liquidação de dívida cambial. A equação estimada utilizando-se a correção de Newey-West para heteroscedasticidade e autocorrelação dos resíduos. n = 480; Média da Variável Dependente $=-0,0496 ;$ Desvio Padrão da Variável Dependente $=0,7334 ; \mathrm{R}^{2}$ Ajustado $=0,003 ; \mathrm{DW}=1,648$.

Os resultados apontam para rejeição da hipótese de retornos anormais na data do vencimento. ${ }^{8}$ Portanto, os resultados de regressão não evidenciam a ocorrência de desvalorização superior da moeda brasileira nos dias anteriores ao vencimento da dívida pública nos anos de 2003 e 2004 e confirmaram a não ocorrência de comportamento anormal no dia do vencimento de dívida pública cambial.

Testou-se também um modelo auto-regressivo com dummies. Utilizando a metodologia geral-específico em busca de um modelo parcimonioso (Hendry, 2001), por meio da eliminação de variáveis não significativas estatisticamente, chegou-se ao modelo apresentado na Tabela 4. A a mostra correspondeu às variações cambiais observadas entre os dias 6 de janeiro de 2003 e 30 de novembro de 2004. Foram incluídas, inicialmente, sete defasagens para a variação cambial e variáveis dummy para o dia do vencimento da dívida e os sete dias anteriores. As variáveis dummy têm valor 1 em caso de ser o dia especificado e 0 para os demais. Foram eliminadas as variáveis não estatisticamente significantes, observados os critérios de Akaike e Schwarz. O melhor modelo inclui apenas a variação passada da taxa de câmbio, em uma defasagem e a variável dummy para o dia do vencimento. Estimou-se a equação via modelo $\operatorname{GARCH}(1,1){ }^{9,} 10 \mathrm{O}$ resultado indica que a variação cambial de um dia corresponde a aproximadamente 0,23 da variação cambial do dia anterior, caracterizando uma certa inércia no comportamento da taxa de câmbio, em que depreciações são usualmente seguidas de novas depreciações e apreciação por apreciação no dia seguinte. Os resultados mostraram ainda uma mudança de intercepto na data do vencimento, indicando retorno anormal da taxa de câmbio nesse dia.

8 Foram feitos testes considerando as datas anteriores ao vencimento em até cinco dias, cujos resultados foram semelhantes.

9 O modelo estimado via MQO apresentou heteroscedasticidade condicional auto-regressiva de ordem relativamente alta (Arch 5). Entretanto, um modelo mais parcimonioso GARCH $(1,1)$, apresentou melhor ajuste da regressão, segundo os critérios de seleção adotados. O modelo (GARCH 1,1) estimado, apresentou-se congruente. A congruência foi verificada por meio do correlograma dos resíduos ao quadrado e os testes LM-Arch, para a correlação serial e heteroscedasticidade dos resíduos, respectivamente. As defasagens no modelo foram escolhidas conforme os critérios Akaike e Schwarz, que indicaram 1 defasagem

10 Estimou-se também um GARCH-M(1,1), mas o aumento da volatilidade, medida pela equação da variância, não apresentou influência significativa para explicar a variação cambial. 
Tabela 4 - Resultado da estimação GARCH(1,1) - variável dependente: variação cambial 20032004

\begin{tabular}{lcccc}
\hline & Coeficientes & Erro Padrão & Estatística $-z$ & Probabilidade \\
\hline Vcto & -0.219 & 0.106 & -2.067 & 0.0386 \\
VarCamb(-1) & 0.226 & 0.0455 & 4.968 & $6.73 \mathrm{e}-07$ \\
\hline \multicolumn{5}{c}{ Equação da Variância } \\
\hline C & 0.010 & 0.003 & 0.0048 \\
Resid $(-1)^{2}$ & 0.195 & 0.038 & 2.819 & $2.59 \mathrm{e}-07$ \\
GARCH $(-1)$ & 0.786 & 0.035 & 5.150 & $1.01 \mathrm{e}-108$ \\
\hline
\end{tabular}

Obs: as variáveis VarCamb e Vcto representam o componente AR(1) da Variação Cambial e a dummy para a data do vencimento de dívida cambial. A equação da variância é uma representação $G A R C H(1,1) \cdot \mathrm{n}=479$; Média da Variável Dependente $=$ -0,0466; Desvio Padrão da Variável Dependente $=0,7312 ; \mathrm{R}^{2}$ Ajustado $=0,039 ; \mathrm{DW}=1,9837$.

Como no período há uma tendência de apreciação da moeda brasileira, a mudança de intercepto pode indicar aceleração da apreciação nesse dia, revertendo eventuais comportamentos mais moderados nos dias anteriores ao vencimento da dívida. Esta estimativa, entretanto, não considerou a possibilidade de a variância das alterações da taxa de câmbio serem influenciadas pelo vencimento da dívida. Isto foi testado incluindo-se no modelo $\mathrm{GARCH}(1,1)$ a variável dummy para os dias anterior e do vencimento de dívida pública cambial. Os resultados são mostrados na Tabela 5.

Tabela 5 - Resultado da estimação GARCH(1,1) - incluindo dummy para o dia anterior e do vencimento - variável dependente: variação cambial 2003-2004

\begin{tabular}{lcccc}
\hline & Coeficientes & Erro Padrão & Estatística z & Probabilidade \\
\hline Vcto & -0.222 & 0.0177 & -12.54 & 0.0000 \\
VarCamb(-1) & 0.225 & 0.0452 & 4.99 & 0.0000 \\
\hline \multicolumn{5}{c}{ Equação da Variância } \\
\hline C & 0.007 & 0.007 & 0.977 & 0.3285 \\
Resid $(-1)^{2}$ & 0.250 & 0.046 & 5.372 & 0.0000 \\
GARCH (-1) & 0.742 & 0.036 & 20.319 & 0.0000 \\
Vcto & 0.110 & 0.037 & 0.980 & 0.0029 \\
Vcto $(-1)$ & -0.061 & 0.023 & -2.603 & 0.0092 \\
\hline
\end{tabular}

Obs: as variáveis VarCamb e Vcto representam o componente AR(1) da Variação Cambial e a dummy para a data do vencimento de dívida cambial. A equação da variância é representada por um $G A R C H(1,1)$ e as dummies para os dias anterior e do vencimento da dívida cambial. $n=479$; Média da Variável Dependente $=-0,0466$; Desvio Padrão da Variável Dependente $=0,7312 ;$ R2 Ajustado $=0,035 ; \mathrm{DW}=1,9825$.

Os resultados indicaram que o dia anterior ao vencimento acarreta aumento da volatilidade cambial, enquanto no dia do vencimento há redução da volatilidade, o que é consistente com o comportamento do mercado financeiro de tentar influenciar a taxa de câmbio no vencimento da dívida, gerando volatilidade em seu comportamento. Para dar robustez a estes resultados foi testado se os efeitos de apreciação e depreciação cambial são simétricos sobre a variância, o que foi implementado pela estimação de um modelo GARCH assimétrico. Os resultados são mostrados na Tabela 6. 
Tabela 6 - Resultado da estimação GARCH(1,1) assimétrico incluindo dummy para o dia anterior e do vencimento - variável dependente: variação cambial 2003-2004

\begin{tabular}{lcccc}
\hline & Coeficientes & Erro Padrão & Estatística $-z$ & Probabilidade \\
\hline Vcto & -0.235 & 0.0465 & -5.06 & 0.0000 \\
VarCamb(-1) & 0.226 & 0.0456 & 4.96 & 0.0000 \\
\hline \multicolumn{5}{c}{ Equação da Variância } \\
\hline C & 0.003 & 0.005 & 0.592 & 0.5534 \\
Resid $(-1)^{2}$ & 0.279 & 0.054 & 5.116 & 0.0000 \\
GARCH $(-1)$ & 0.787 & 0.036 & 21.607 & 0.0000 \\
Vcto & -0.050 & 0.206 & -2.453 & 0.0142 \\
Vcto $(-1)$ & 0.121 & 0.034 & -3.562 & 0.0004 \\
DRN & -0.135 & 0.055 & -2.426 & 0.0153 \\
\hline
\end{tabular}

Obs: as variáveis VarCamb e Vcto representam o componente AR(1) da Variação Cambial e a dummy para a data do vencimento de dívida cambial. A equação da variância é representada por um $G A R C H(1,1)$, as dummies para os dias anterior e do vencimento da dívida cambial e DRN é o threshold para captar o efeito assimétrico na taxa de câmbio. $n=479$; Média da Variável Dependente $=-0,0466$; Desvio Padrão da Variável Dependente $=0,7312 ;$ R2 Ajustado = 0,033; DW $=1,9842$.

Os resultados da Tabela 6 mostram que existe um efeito assimétrico para apreciações e depreciações da taxa de câmbio, após controlado o efeito dos vencimentos da dívida pública. ${ }^{11} \mathrm{O}$ coeficiente estimado para a variável dummy com valor 1, quando o resíduo da estimativa da variação cambial é menor que zero, tem valor negativo, o que indica que as apreciações da moeda brasileira superiores ao previsto no modelo estão associadas a reduções da sua volatilidade, o que é compatível com a intuição de que as quedas de preço do dólar são lentas enquanto as subidas acontecem em movimentos rápidos.

\subsection{Mudança markoviana}

Por fim, com o intuito de verificar se existe algum tipo de alteração no retorno da taxa de câmbio R \$/US\$ em 2003 e 2004, estimou-se um modelo de mudança de regime markoviano univariado para a primeira diferença da série de taxa de câmbio. Escolheu-se apenas uma defasagem devido aos resultados obtidos no modelo linear.

Um problema que surge nos modelos markovianos de mudança de regime é a determinação do número de regimes. Os testes de razão de verossimilhança para a determinação do número de regimes não têm distribuição assintótica padrão devido à existência de parâmetros incômodos (nuisance parameters). Porém, no presente trabalho, devido ao interesse de se observar a existência de retornos anormais nos dias que antecedem o vencimento de títulos públicos cambiais, o número de regimes seria conhecido e igual a dois. Um regime seria formado por datas onde o retorno da taxa de câmbio não se afasta demasiadamente da média, enquanto o segundo regime seria formado por datas em que o retorno da taxa de câmbio é alterado de forma anormal.

Todavia, como o processo de mudança de regimes é não observável, nada garante que ele seja determinado pelos retornos excessivos em dias anteriores ao vencimento de títulos da dívida pública. Portanto, para identificar o número de regimes, utilizam-se os critérios de Akaike e Schwarz que nunca subestimam o número de regimes (Rydén, 1995).

11 Os resultados da estimação de um modelo GARCH-M foram semelhantes aos da Tabela 6, com efeito assimétrico estatisticamente significativo na variância, mas sem efeito significativo da equação da variância sobre a variação cambial. 
Para encontrar o modelo mais apropriado foram estimados modelos lineares, com dois e com três regimes. Os modelos com mudança de regime são estimados com mudança na média ou modelo com mudança no intercepto. Os critérios de informação de Akaike, Schwarz e HannanQuinn (Tabela 7) indicam o modelo com três regimes e mudança no intercepto. As mudanças no intercepto não têm relação com o vencimento de títulos da dívida brasileira atrelada ao câmbio, pois as datas não coincidem. O que se percebe é a existência de três regimes caracterizados por retornos negativos, nulos e positivos da taxa de câmbio (Tabela 8).

A Figura 1 mostra o gráfico com as probabilidades filtradas, suavizadas e previstas, onde fica clara a relação de dependência entre os regimes de retornos positivos e negativos, mostrando que, logo após um período, sempre curto, de retornos positivos, tem-se um período de retornos negativos, também curto. Isso reforça a idéia de mercados eficientes, mostrando apenas que a freqüência de nossos dados é maior do que a habilidade do mercado de zerar os retornos. Também na Figura 1 pode-se ver que o regime de maior duração, o único que se mantém por um longo período de tempo, é o regime de retornos nulos, também de acordo com a hipótese de mercados eficientes. Outra evidência contra a existência de dois regimes é o melhor ajuste, segundo os critérios de informação AIC, HQC e BIC, do modelo AR(1) linear em contraste com o modelo não-linear MSI(2) AR(1) (Tabela 7).

Tabela 7 - Testes para modelo de mudança de regime markoviano

\begin{tabular}{llll}
\hline Modelo & AIC & HQC & BIC \\
\hline MSM(2) & -4.5790 & -4.5501 & -4.5068 \\
MSI(2) & -4.5790 & -4.5502 & -4.5790 \\
MSM(3) & -4.9681 & -4.9286 & -4.8680 \\
MSI(3) & -4.9696 & -4.9301 & -4.8695 \\
Linear & -4.5984 & -4.5840 & -4.5623 \\
\hline
\end{tabular}

Tabela 8 - Resultados do modelo de mudança de regime markoviano - 2003 e 2004

\begin{tabular}{lccc}
\hline Parâmetro & Coeficiente & Desvio Padrão & Estatística $t$ \\
\hline Constante (Regime 1) & -0.0298 & 0.0024 & -12.170 \\
Constante (Regime 2) & -0.0006 & 0.009 & -0.706 \\
Constante (Regime 3) & 0.0328 & 0.0034 & 9.672 \\
VarCamb (-1) & 0.1614 & 0.0475 & 3.3957 \\
\hline
\end{tabular}

Obs: valores em negrito denotam aceitação da hipótese nula de que o valor do coeficiente é igual a zero. 
Figura 1 - Probabilidade de mudança de regime markoviano - 2003 e 2004

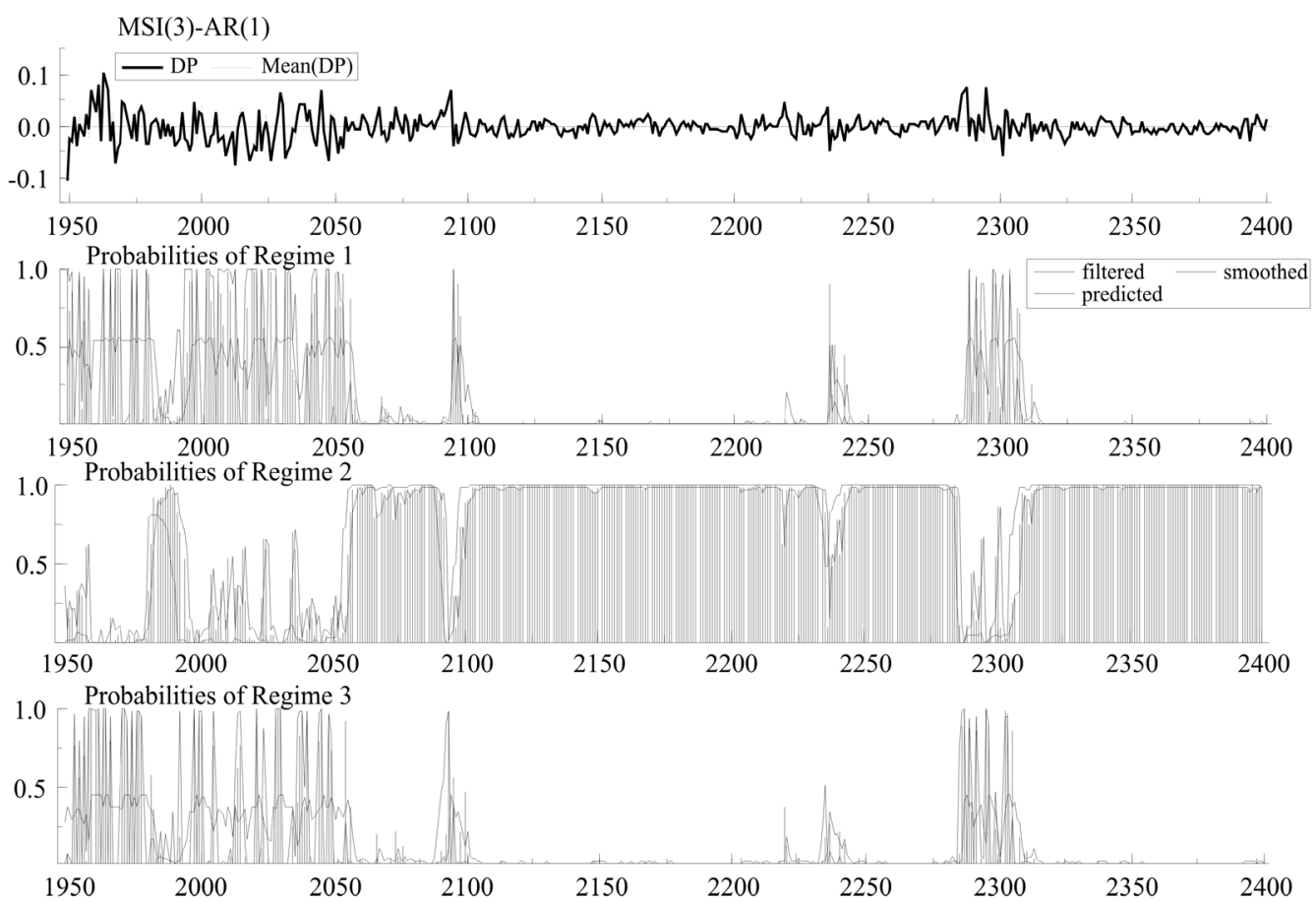

Para testar a robustez dos resultados do modelo markoviano, variáveis dummy para o dia anterior e para o dia do vencimento foram incluídas. Os resultados apresentados na Tabela 9 confirmam os resultados do modelo sem dummies, uma vez que estas não são significativas. Portanto, utilizando-se modelos não-lineares com mudança de regime markoviano, rejeita-se a hipótese de influência na taxa de câmbio nos dias anteriores ou no próprio dia do vencimento de títulos públicos atrelados ao dólar para o período estudado. Também foi detectado comportamento auto-regressivo da variação cambial, com a variação de um dia, sendo 0,16 da variação do dia anterior.

Tabela 9 - Resultados do modelo de mudança de regime markoviano com dummy-2003-2004

\begin{tabular}{lccc}
\hline Parâmetro & Coeficiente & Desvio Padrão & Estatística $t$ \\
\hline Constante (Regime 1) & -0.0300 & 0.0024 & -12.304 \\
Constante (Regime 2) & -0.0008 & 0.0010 & -0.806 \\
Constante (Regime 3) & 0.0328 & 0.0034 & 9.709 \\
VarCamb (-1) & 0.159 & 0.0464 & 3.438 \\
Vcto & 0.004 & 0.0025 & 1.486 \\
Vcto (-1) & -0.002 & 0.0025 & -0.941 \\
\hline
\end{tabular}

Nota: Valores em negrito denotam aceitação da hipótese nula de que o valor do coeficiente é igual a zero. 
Em termos gerais, os resultados indicaram a rejeição da hipótese de sinalização. Não se pôde constatar a presença de retornos anormais no período precedente ao vencimento da dívida pública cambial. Para o dia do vencimento, os testes de Mann-Whitney, Wilcoxon e o modelo GARCH detectaram comportamento diferente da taxa de câmbio, em que pode ocorrer aceleração da apreciação do real que ocorreu em 2003 e 2004, após estabelecida a taxa de câmbio utilizada para liquidar a dívida. Os resultados não são conclusivos, com evidência de comportamento anormal da taxa de câmbio no dia do vencimento de dívida cambial pelos testes de Mann-Whitney e Wilcoxon, que não permite verificar qual é esta alteração, e pelo modelo GARCH com variável dummy, que indica apreciação anormal e alterações de volatilidade. O modelo GARCH detectou um comportamento assimétrico da variância dos retornos cambiais, maior para depreciações do que para apreciações da moeda brasileira. Estes comportamentos não foram detectados pelo modelo de mudança markoviana. Portanto, há maiores evidências de que há mudança na volatilidade da taxa de câmbio do que sobre o efeito na própria variação da taxa.

\section{CONCLUSÕES}

Neste trabalho procurou-se verificar a ocorrência de uma depreciação anormal da moeda brasileira em relação ao dólar dos Estados Unidos nos dias que antecedem o vencimento de dívida pública cambial brasileira. Este fenômeno, referido freqüentemente no noticiário financeiro, estaria associado a uma manipulação da taxa de câmbio por parte de detentores da dívida, os quais seriam favorecidos por taxas de câmbio mais elevadas. Como a taxa utilizada para a liquidação da dívida é a ptax (taxa média) do dia anterior, haveria interesse em elevar a taxa antes do vencimento. Todavia, em termos gerais não foi possível detectar movimento anormal da taxa de câmbio nos dias anteriores ao vencimento da dívida interna cambial.

Ambos os testes, não-paramétricos (Mann-Whitney e Wilcoxon) e paramétricos (regressão linear com variável dummy e não-linear com GARCH e mudança markoviana), rejeitaram a hipótese de ocorrência de desvalorização superior da moeda brasileira nos dias anteriores ao vencimento da dívida pública nos anos de 2003 e 2004. O modelo de mudança markoviana não detectou comportamento anormal da variação cambial no dia do vencimento de dívida pública cambial. $\mathrm{O}$ teste de Mann-Whitney e Wilcoxon e o modelo GARCH detectaram comportamento diferente do câmbio no dia do vencimento da dívida, quando já não haveria interesse em elevar a cotação do dólar. A dummy multiplicativa (retirada do modelo GARCH) não foi significativa, indicando que não houve mudança na inclinação. Entretanto, a dummy de intercepto indicou a presença de retornos anormais para a data do vencimento, uma maior apreciação da moeda brasileira. Portanto, a hipótese de que a proximidade da data de vencimento da dívida pública poderia sinalizar ganhos extraordinários no mercado de câmbio foi rejeitada, mas há indício de comportamento diferente da taxa de câmbio após definida a taxa com a qual será liquidada a dívida. Entretanto, verificou-se comportamento anormal da volatilidade da taxa de câmbio e comportamento assimétrico quando ocorrem depreciações e apreciações da moeda brasileira.

Há possibilidade, portanto, de que os detentores da dívida cambial tenham conseguido frear a apreciação do real nos dias anteriores ao vencimento da dívida, apreciação que se acelerou no dia do vencimento da dívida pública cambial. Os resultados são mistos, porque o modelo de mudança markoviana não detectou comportamento distinto, os testes de Mann-Whitney e Wilcoxon não permitem verificar se é a média que é distinta, embora tenha sido detectado comportamento diferente da taxa de câmbio no dia do vencimento da dívida pública. No modelo GARCH é que se detecta o 
possível comportamento da taxa de câmbio favorável aos detentores da dívida, por maior apreciação do real, depois de definida a taxa de câmbio para liquidação da dívida.

\section{REFERÊNCIAS BIBLIOGRÁFICAS}

Brennan, M. J.; Copeland, T. E. Stock splits, stock prices, and transation costs. Journal of Financial Economics $\mathrm{n} .22,1988$, p. 83-101.

Britto, N. R. O.; Taciro Jr., A. C. Características da relação entre as taxas SELIC e CDI e suas implicações. Revista de Economia e Administração, jul.-set. 2002, p. 35-51.

Brooks, R. et al. The national market impact of sovereign rating changes. Journal of Banking \& Finance, v. 28, n. 1, 2004, p. 233-250.

Dempster, A. P.; Laird, N. M.; Rubin, D. B. Maximum likelihood from incomplete data via the EM algorithm. Journal of The Royal Statistical Society. Série B, 39, 1977, p. 1-38.

Evans, Martin D. D.; Lyons, R. K. A new micro model of exchange rate dynamics. NBER Working Paper 10379. Disponível em: <http://www.nber.org/papers/w10379>. Acesso em: abr. 2004.

Fama, E. et al. The adjustment of stock prices to new information. International Economic Review n. 10, 1969, p. 1-21.

Garcia, M. G. P.; Urban, F. O mercado interbancário de câmbio no Brasil, 2004 . Disponível em: <http://www.econ.puc-rio.br/Mgarcia/Papers/ Garcia\&Urban040325.PDF>. Acesso em: 13 abr. 2004. Mimeografado.

Garofalo Filho, E. É hora de transparência. Notícias ABBC, Associação Brasileira de Bancos, n. 77, set./out., 2002a, p. 1-2. 2002 b.

. Câmbio, ouro e dívida externa - de Figueiredo a FHC. São Paulo: BM\&F/Saraiva,

Grimblatt, M. S.; Masulis, R. W.; Titman, S. The valuation effects of stock splits and stock dividends. Journal of Financial Economics, n. 13, 1984, p. 461-490.

Hamilton, J. D. Time series analysis. Princeton University Press: Princeton, NJ, 1994.

Hendry, D. F. Achievements and challenges in econometric methodology. Journal of Econometrics, v. 100, n. 1, 2001, p. 7-10.

Huberman, G.; Stanzl, W. Price manipulation and quasi-arbitrage. Econometrica, v. 72 n. 4, 2004, p. 1247-1275.

Kadiyala, P.; Vetsuypens, M. R. Are stock splits credible signals? Evidence from short-interest data. Financial Management, v. 31, 2002, p. 31-49.

Krolzig, H. M. Markov-switching vector autoregressions. Springer-Verlag: Berlin, 1997.

Kyle, A. S. Continuous auctions and insider trading. Econometrica, v. 53, n. 6, 1985, p. 1315-1335.

Lakonishok, J.; Lev, B. Stock splits and stock dividends: why, who, and when. Journal of Finance, n. 42, 1987, p. 913-932.

Lyons, R. K. Optimal transparency in a dealer market with an application to foreign exchange. Journal of Financial Intermediation, n. 5, 1996, p. 225-254.

. A simultaneous trade model of the foreign exchange hot potato. Journal of International Economics, v. 42, n. 3-4, 1997, p. 275-298.

Mackinlay, C. A. Event studies in economics and finance. Journal of Economic Literature, v. XXXV, Mar. 1997, p. 13-39. 
Malik, F. Sudden changes in variance and volatility persistence in foreign exchange markets. Journal of Multinational Financial Management, v. 13, 2003, p. 217-230.

Mann, H. B.; Whitney, D. R. On a test of whether one of 2 random variables is stochastically larger than the other. Annals of Mathematical Statistics, 18, 1947, p. 50-60.

Payne, R.; Vitale, P. A transaction level study of the effects of central bank intervention on exchange rates. Journal of International Economics, v. 61, n. 2, 2003, p. 331-352.

Rydén, T. Estimating the order of hidden Markov models. Statistics, v. 26, 1995, p. 345-354.

Sheskin, D. J. The Handbook of parametric and nonparametric statistical procedures. Chapman and Hall, 2004.

Tabak, B. M. Monetary policy surprise and Brazilian terms structure of interest rate. Banco Central do Brasil, Trabalho para Discussão 70, 2003. Disponível em: <http://www.bcb.gov.br/pec/wps/port/wp70. asp? idiom $=$ P > . Acesso em: 16 abr. 2004.

Wilcoxon, F. Individual comparisons by ranking methods. Biometrics, v. 1, n. 6, 1945, p. 80-83. 